\title{
Immunostimulatory Response of RWFV Peptide- Targeted Lipid Nanoparticles on Bladder Tumor Associated Cells
}

Shayak Samaddar, Joshua Mazur, Jessica Sargent ${ }^{+}$, David H. Thompson*

Multi-disciplinary Cancer Research Facility, Bindley Bioscience Center, Department of Chemistry, Purdue University, West Lafayette, IN 47907

+ Current address: Women in Engineering Program, Purdue University, 610 Purdue Mall, West Lafayette, IN 47907

* Corresponding author: davethom@purdue.edu 


\section{Lipid Stream: $\mathbf{5 0 0} \mu \mathrm{l} / \mathrm{min}$ (MeOH)}

CHEMS DOTAP

DOPE RWFV-PEG2k-DSPE

CpG Stream: $1500 \mu \mathrm{l} / \mathrm{min}$

CpG in 20 mM HEPES buffer

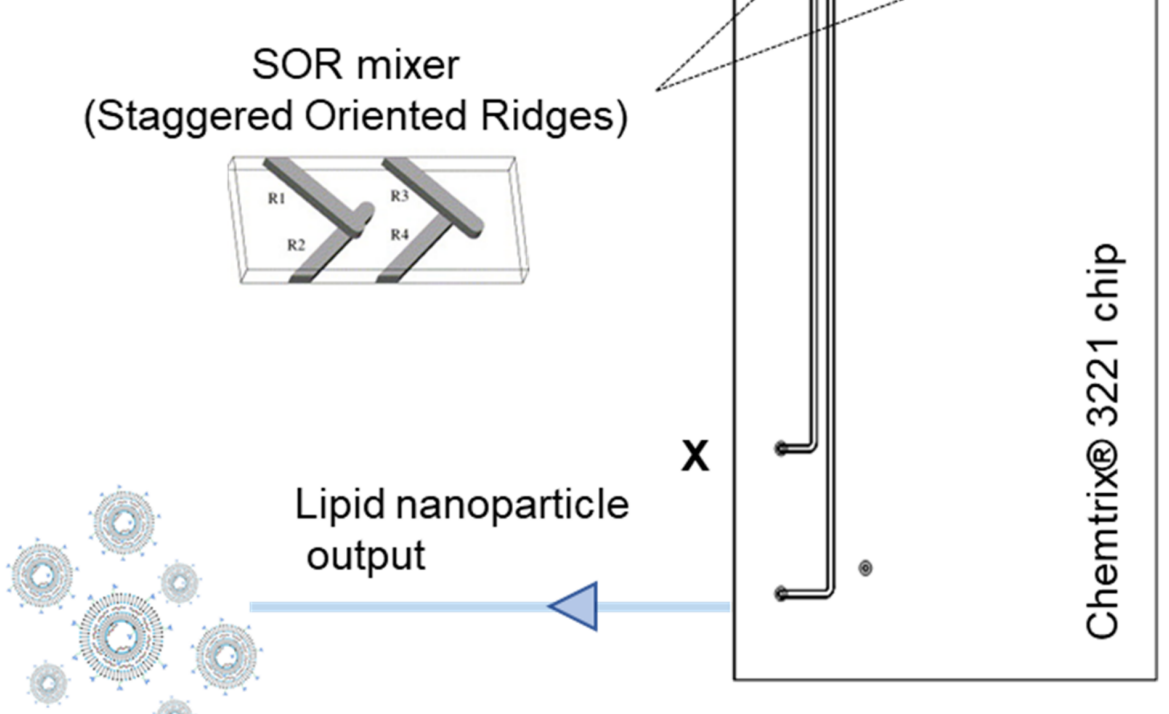

Figure S1. Schematic representation of LNP formulation using a Chemtrix 3221 microfluidic chip. 

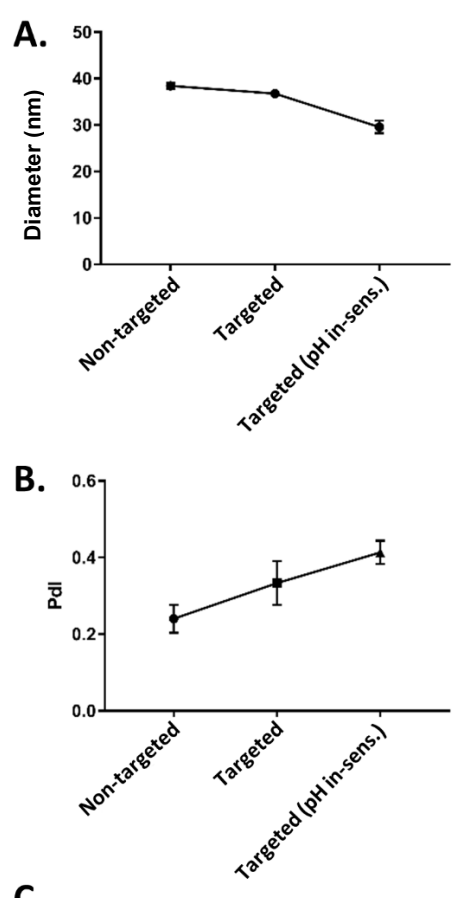

C.

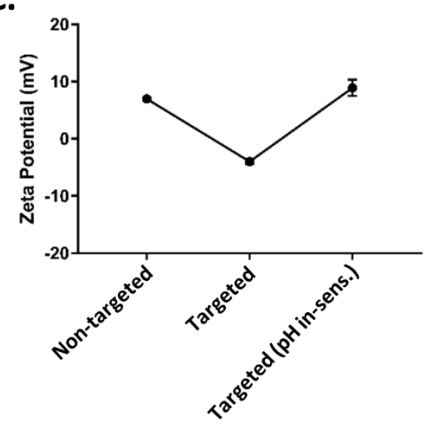

Figure S2. Physicochemical characterization of developed formulations at N/P of 5 (A) Diameter; (B) Polydispersity Index (PdI); and (C) Zeta Potential. Results are the mean \pm SD ( $n=3$ ). (Non-targeted: 45:30:23:2 DOTAP:DOPE:CHEMS: $\mathrm{mPEG}_{2 \mathrm{~K}}$-DSPE, Targeted: 45:30:23:2 DOTAP:DOPE:CHEMS:RWFV-PEG ${ }_{2 \mathrm{~K}}-\mathrm{DSPE}$, Targeted pH-insensitive: 45:30:23:2 DOTAP:DOPE:CHOL:RWFV-PEG ${ }_{2 K}$-DSPE). 


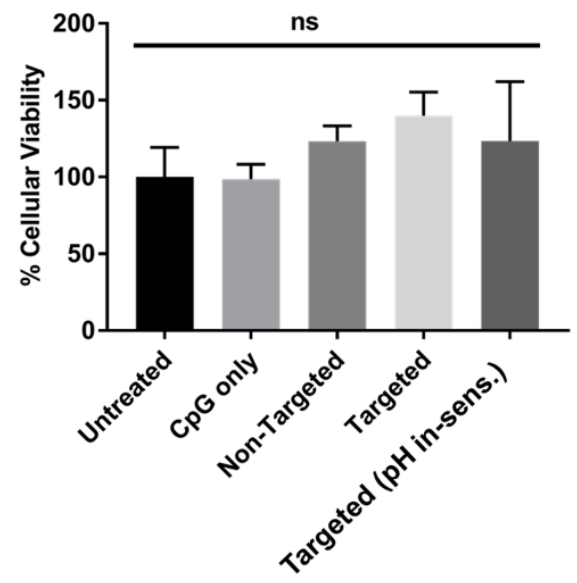

Figure S3. Cytotoxicity analysis of LNP on MB49 cells. (Non-targeted: 45:30:23:2 DOTAP:DOPE:CHEMS:mPEG ${ }_{2 K}$-DSPE; Targeted: 45:30:23:2 DOTAP:DOPE:CHEMS:RWFV-PEG ${ }_{2 K}-D S P E$, Targeted pH-insensitive: 45:30:23:2 DOTAP:DOPE:CHOL:RWFV-PEG $\left.{ }_{2 K}-D S P E\right)$. Cells were treated with LNP formulations at a $\mathrm{CpG}$ dose of $1 \mu \mathrm{g} / \mathrm{mL}$ for $2 \mathrm{~h}$ at $37^{\circ} \mathrm{C}$ followed by PBS wash. Cells were further incubated for $12 \mathrm{~h}$ in FBS supplemented media. Cytotoxicity was measure by MTS assay. Error bars indicate standard deviation of the mean ( $\mathrm{n}=3$, one-way ANOVA, $\mathrm{p}=\mathrm{ns}$ ) 